\title{
Multifunctional CuO Nanoparticles with enhanced photocatalytic dye degradation and antibacterial activity
}

\section{Kanika Dulta}

Shoolini University

Gözde Koşarsoy Ağçeli

Shoolini University

Parveen Chauhan

Shoolini University

Rohit Jasrotia

Shoolini University

\section{Gourav Chandan}

Shoolini University

Pankaj Kumar Chauhan ( $\nabla$ chauhanbiochem084@gmail.com )

Shoolini University https://orcid.org/0000-0002-3077-8206

\section{Research Article}

Keywords: B. ciliata, copper oxide, nanoparticle, antimicrobial, photocatalytic

Posted Date: March 22nd, 2021

DOl: https://doi.org/10.21203/rs.3.rs-346220/v1

License: (9) (i) This work is licensed under a Creative Commons Attribution 4.0 International License. Read Full License

Version of Record: A version of this preprint was published at Sustainable Environment Research on January 6th, 2022. See the published version at https://doi.org/10.1186/s42834-021-00111-w. 


\section{Abstract}

Rhizome extract of Bergenia ciliata was used as a bio-functional reducing material for green synthesis of copper oxide nanoparticles (CuO NPs). CuO NPs were characterized using ultra violet-visible spectroscopy (UV-vis), fourier transform infrared spectroscopy (FTIR), X-ray diffraction (XRD), dynamic light scattering (DLS), scanning electron microscopy (SEM) and energy-dispersive X-ray analysis (EDX). XRD analysis revealed the monoclinic phase of synthesized CuO NPs with average particle size of $20 \mathrm{~nm}$. Spherical shaped nanoscale $\mathrm{CuO}$ particles were observed by EDX and SEM confirming the $\mathrm{Cu}$ and $\mathrm{O}$ presence in the synthesized nanoparticles. CuO nanoparticles showed antibacterial effects against all bacteria used in the study. The antioxidant effect was measured and $\mathrm{IC}_{50}$ values for $A B T S, D P P H$ and FRAP assays were found to be $91.2,72.4$ and $109.0 \mu \mathrm{g} / \mathrm{mL}^{-1}$ respectively. Under sunlight, the CuO NPs reported extraordinary photocatalytic activity against methylene blue and methyl red degradation with efficiencies of 92 and 85 percent, respectively. CuO NPs have excellent potential application for the photocatalytic degradation of organic pollutant and in the development of antibacterial materials and for the first-time effect of these nanoparticles were reported.

\section{Introduction}

Nanotechnology, one of the most important research areas in material science. This field is remarked as rapidly growing field of science and engineering as important research are carried out [1-5].

Nanomaterials have an important place in many areas owing to their thermal properties, surface areas, particle size, electrical conductivity [6-9]. Nanoparticles, which are part of nanomaterials, have many uses in the food, pharmaceutical, energy industry, biotechnology and biomedicine [10-13]. Different chemical and physical methods are used for the production of metallic nanoparticles [14]. High toxic substances and unnecessary energy consumption in these methods are not acceptable. For this reason, green chemistry and bioprocesses have been developed for the synthesis to be carried out in a reliable, environmentally friendly, economical and biocompatible [15]. Biosynthesis using fungi, bacteria and plants and green chemistry open new horizons in nanoparticle production $[16,17]$. Plants with regions such as leaves, gum and fruit are also involved in metal nanoparticle synthesis and used in antimicrobial [18], anticancer [19, 20], antioxidant [21], nanomedicine [22], and diagnostic studies [23, 24]. Alkaloids, flavonoids and other natural compounds, plants function as powerful reducers and stabilizers [25]. When we look at the copper nanoparticles, it draws attention among other metal oxide nanoparticles in many applications (eg optics, antimicrobial, catalytic, etc.) [26]. In addition, its cost and availability are more advantageous compared to Ag, Au and Pt metals. Copper has long been used antimicrobial agent, it has low toxicity and it is very important in the biomedical [27]. The band gap of copper oxide is $\sim 1.7 \mathrm{eV}$ and this type-p has a semiconductor feature in nonclinical structure [28]. The simplest member of the copper compound family, $\mathrm{CuO}$ has many useful physical properties [29]. It has an important place in many fields such as solar energy conversion, high temperature superconductors, gas sensors etc [30]. Copper oxide NPs (CuO NPs) are the most widely used metal NPs for waste water treatment because of their superior catalytic properties. Bergenia ciliata (Haw.) Sternb. belongs to family Saxifragaceae and is mostly 
distributed in the cold and temperate regions. It is found in traditional medicines and ayurveda for use in the treatment of different diseases and it is used in countries such as Pakistan, India, Bhutan [31]. Lung infections, fever, diarrhea and dissolution of kidney stones can be treated with $B$. ciliata in India medicine [32]. Besides, anti-tussive activity [33], anti-inflammatory effect, analgesic, diuretic feature[34], antioxidant activity, DNA protection [31], immunity enhancement can be achieved with this plant. $B$. ciliata has many phytochemicals (e.g. paashaanolactone [35], catechin, bergerin and gallic acid) [36]. Therefore, in present work, we have adopted green chemistry approach for the synthesis of copper oxide NPs (CuO NPs) from B. ciliata extract. Shape and size of particles were characterized using various standard techniques, such as UV-vis, FTIR, SEM, XRD, DLS, EDAX and electrochemical studies. Furthermore antioxidant, antibacterial and photocatalytic activity of the CuO NPs are also discussed.

\section{Material And Methods}

\subsection{Collection of Plant Material and Synthesis of CuO NPs}

Rhizomes of Bergenia ciliata were collected from the Narkanda area of district Shimla, Himachal Pradesh, India during spring season from April to June, 2019. For the production of CuO NPs Bergenia ciliata rhizome was washed d-water, followed by shadow drying for 10-12 days. The dried rhizomes were grinded to fine powder and $10 \mathrm{~g}$ of ground powder was added to $100 \mathrm{~mL}$ of d-water and boiled for 10 minutes at $60^{\circ} \mathrm{C}$. The cooled extract was filtered through Whatman No.1 filter paper and put into the refrigerator until it was used. Synthesis of $\mathrm{CuO}$ nanoparticles by green method was carried out by modifying the work of Sankar et al. [37]. Copper sulphate (Himedia) were used as the precursor. $5 \mathrm{mM}$ (CuSO ${ }_{4} \cdot 5 \mathrm{H}_{2} \mathrm{O}$ ) solution of $90 \mathrm{~mL}$ was mixed with $10 \mathrm{~mL}$ filtrate and incubated at $25^{\circ} \mathrm{C}$ until further colour change occurs. Colour change was evaluated by comparison with (Extract and Copper sulphate) the control solution to determine whether nanoparticles were synthesized. The synthesized CuO NPs were further subjected to characterization studies.

\subsection{Characterization of CuO NPs}

Shimadzu UV-Vis V-530A spectrophotometer was used to measure the UV-Visible absorption spectra of the samples, which ranged from 200 to $600 \mathrm{~nm}$. The FTIR spectrum (Perkin-Elmer-Spectrum Two) was obtained at a wavelength of $400-4000 \mathrm{~cm}^{-1}$. Energy dispersive X-ray analysis (EDAX) and elemental mapping were also performed using this device. CuO NPs XRD pattern was determined using the same instrument at Indian Institute of Technology, Mandi, using a powder X-ray diffractometer (Philips X'Pert Pro X-ray diffractometer) with $\mathrm{Cu}(\mathrm{Ka})$ radiations $(1.5406 \AA)$ in a $2 \theta$ range from $30^{\circ} \mathrm{C}$ to $80^{\circ} \mathrm{C}$. Dynamic light scattering (DLS) analysis of copper oxide nanoparticles was performed using a DynaPro Plate Reader (Wyatt Technology). Scanning electron microscopy (SEM-Hitachi/s-4200 N) was used to show the shape and morphology of copper oxide NPs.

\subsection{Analysis of electrochemical study:}


Electrochemical study of CuO Nanoparticles synthesized using green technology was carried out on an analytical model of Palmsense 4 (Potentiostat/ Galvanostat/ Impedance Analyser) on PS Trace software. Certain amount of green synthesized CuO NPs were analysed on Dropsens (DS-110) electrodes against bare electrode, each treated with EDC: NHS (1:1). Cyclic Voltammetry analysis was performed at different scan rates $(20 \mathrm{mV} / \mathrm{s}, 40 \mathrm{mV} / \mathrm{s}, 60 \mathrm{mV} / \mathrm{s}$ and $100 \mathrm{mV} / \mathrm{s})$ using $2.5 \mathrm{mM}$ potassium ferricyanide $\left(\mathrm{K}_{3}\left[\mathrm{Fe}(\mathrm{CN})_{6}\right)\right.$ redox indicator. Washing off electrodes after consecutive measurements using Phosphate buffer Saline $(\mathrm{pH}-7.4)$ and Tris -EDTA $(\mathrm{pH}-8.0)$ as wash buffers.

\subsection{Quantification of phenolic and flavonoid content}

Rhizome extract of Berginia ciliata (BC) and copper oxide nanoparticles (CuO NPs) were analysed for phenolic and flavonoid content using standard procedures.

\subsubsection{Total phenolic content}

Total phenolic content was measured using the Folin-Ciocalteu test following the updated procedure described by Singleton [38]. For the preparation of regular extract solutions, $5 \mathrm{mg}$ of each sample was dissolved in $5 \mathrm{~mL}$ of methanol. $1 \mathrm{~mL}$ Folin-Ciocalteu reagent was weighed and diluted with distilled water to form $10 \mathrm{~mL}$. Each extract's working standards were made by combining $1 \mathrm{~mL}$ standard solution with 9 $\mathrm{mL}$ distilled water. Each test tube was added with $1 \mathrm{~mL}$ of diluted Folin-Ciocalteu reagent, which was allowed to stand for 6 minutes, followed by addition of distilled water and incubation for 90 minutes at room temperature, $10 \mathrm{~mL}$ of $7 \%$ sodium carbonate solution was then added to the reaction mixtures in each test tube and further diluted to $25 \mathrm{~mL}$. UV spectrophotometer was used to determine the sample's absorbance at760 $\mathrm{nm}$. The equivalent milligrams of gallic acid (mg GAE / g) per gram of dry sample was used to determine the total phenolic content.

\subsubsection{Total flavonoid content}

Total flavonoid content was determined by the aluminum chloride colorimetric assay according to the method described by Meda [39]. In $5 \mathrm{~mL}$ methanol, approximately $5 \mathrm{mg}$ of each extract was dissolved, from each of these normal solutions, $1 \mathrm{~mL}$ was diluted with $9 \mathrm{~mL}$ distilled water and then with $1 \mathrm{~mL}$ $\mathrm{NaNO}_{2}(5 \%)$. The mixtures were allowed to stand $6 \mathrm{~min}$ for a continued reaction. Then $2 \mathrm{~mL}$ of $10 \%$ aluminum chloride solution was applied to each and allowed to stand for 5 minutes. Then the mixtures were added with $2 \mathrm{~mL}$ of sodium hydroxide ( $1 \mathrm{M}$ ) in series. Eventually, a UV spectrophotometer was used to measure the absorbance of the mixture at $510 \mathrm{~nm}$. The total content of flavonoids was measured as milligrams of equivalent rutin ( $\mathrm{mg} \mathrm{QE} / \mathrm{g}$ ) per gram of dry sample.

\subsection{Antioxidant effect of CuO NPs}

\subsubsection{ABTS radical scavenging assay}

For ABTS assay, a predefined method [40] with some modifications was performed. CuO NPs were added one by one with $3 \mathrm{~mL}$ of $0.1 \mathrm{mM}$ ABTS and incubated in the dark for 15 minutes at varying 
concentrations ( 12.5 to $100 \mathrm{~g} / \mathrm{mL}$ ). At $745 \mathrm{~nm}$, the degree of colour removal was observed. CuO NPs were added one by one with $3 \mathrm{~mL}$ of $0.1 \mathrm{mM}$ ABTS and incubated in the dark for 15 minutes at varying concentrations ( 12.5 to $100 \mathrm{~g} / \mathrm{mL}$ ). At $745 \mathrm{~nm}$, the degree of colour removal was observed. Without any sample, the ABTS reagent was used as a control solution and ascorbic acid used as standard. The scavenging inhibition capacity was measured;

ABTS radical scavenging activity $(\%)=\left(A_{\text {control }} A_{\text {test }}\right) / A_{\text {control }} \times 100$

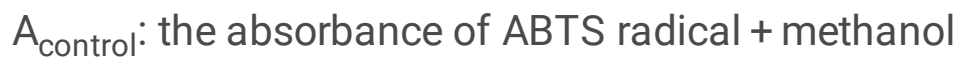

$A_{\text {test }}$ : the absorbance of ABTS radical + sample/standard.

\subsubsection{DPPH Radical Scavenging assay}

The DPPH assay was performed according to some modifications in predefined method [41]. CuO NPs were added one by one to $3 \mathrm{~mL}$ of $0.1 \mathrm{mM} \mathrm{DPPH}$ and incubated in the dark for 15 minutes at different concentrations (12.5 to $100 \mathrm{~g} / \mathrm{mL}$ ). At $745 \mathrm{~nm}$, the degree of colour removal was observed. Without sample, DPPH methanol reagent was used as control solution and ascorbic acid used as standard.

The mixture was thoroughly prepared and held at $25^{\circ} \mathrm{C}$ for 30 minutes in the dark. At a wavelength of 517 $\mathrm{nm}$, the absorbance was determined using a spectrophotometer. The following equation was used to measure the samples' scavenging potential:

DPPH radical scavenging activity $(\%)=\left(A_{\text {control }} A_{\text {test }}\right) / A_{\text {control }} \times 100$

$\mathrm{A}_{\text {control: }}$ the absorbance of DPPH radical + methanol

$A_{\text {test }}:$ the absorbance of DPPH radical + sample/standard.

The $\mathrm{IC}_{50}$ value, which represents the effective concentration of extract / standard required to scavenge $50 \%$ of DPPH radicals, was used to measure the scavenging behaviour of the samples.

\subsubsection{Ferric reducing antioxidant power assay (FRAP)}

Following Benzie and Strain's protocol, the antioxidant potential of the samples was determined spectrophotometrically [42]. The method relies on the reduction of $\mathrm{Fe}^{3+}$ tripyridyltriazine complex (colourless complex) to $\mathrm{Fe}^{2+-}$ tripyridyltriazine (blue coloured complex) by electron donating antioxidants at low $\mathrm{pH}$. The shift in absorbance at $593 \mathrm{~nm}$ is used to monitor this reaction.

\subsection{The antimicrobial assay}

Green-synthesized copper oxide NPs were tested on Bacillus subtilis, Staphylococcus aureus, Escherichia coli, Salmonella typhi. The microorganisms were procured from the Department of Food Technology of Shoolini University Solan, Himachal Pradesh, India. The antimicrobial activity was determined by well diffusion method [43]. Individual microorganisms were cultured in 100L of mature broth culture for 24 
hours on nutrient agar plates. Sterile cork borer was used to produce $6 \mathrm{~mm}$ diameter wells in a petri dish. $20 \mathrm{mg} / \mathrm{mL}$ of plant extract and CuO NPs were used to assess the activity. The standard antibiotic Streptomycin $(50 \mathrm{mg} / 5 \mathrm{~mL}$ ) was used as a positive control, whereas distilled water was used as a negative control. The zone diameter was measured in millimetres after the cultures were incubated at $37^{\circ} \mathrm{C}$ for 24 hours. The experiment was repeated three times.

The minimum inhibitory concentration (MIC) was determined using the broth dilution method, as explained [44]. The positive and negative controls for the MIC test are $10 \mu \mathrm{L}$ Ampicillin (100 $\mathrm{mg} / \mathrm{mL}$ stock) and $10 \mu \mathrm{L}$ MilliQ water, respectively. $100 \mu \mathrm{L}$ of CuO NPs $(1 \mathrm{mg} / \mathrm{mL})$ were incubated in a 96-well microtiter plate and incubated at $37^{\circ} \mathrm{C}$ for 24 hours. Resazurin sodium dye was added to the wells to see the results after incubation, color change from purple to pink or colorless. The lowest concentration of this color change was accepted as the MIC value of $\mathrm{CuO}$ nanoparticles against the test microorganisms used in the study.

\subsection{Photocatalytic activities}

Under sunlight irradiation, the photocatalytic behaviors of $\mathrm{CuO}$ NPs were analyzed for the degradation of methylene blue (MB) and methyl red (MR) dyes. A beaker was filled with $10 \mathrm{ml}(20 \mathrm{ppm})$ of dyes for the reaction, approximately $10 \mathrm{mg}$ of $\mathrm{CuO}$ NPs were added to the dye solutions as-prepared, followed by stirring of reaction mixture for 15 minutes in dark. Thereafter, the reaction mixture was kept in the sunlight for $15,30,45,60,75,90,105,120$, and 135 minutes. The experiment was conducted outside in the sunlight, with the adsorption/desorption balance being constantly stirred. After the reaction, the CuO NPs were centrifuged out of solution, and the dye concentration was measured using the UV-visible spectrum. After a period of time, the amplitude of the MB and MR absorbance peaks (at 625 and $525 \mathrm{~nm}$ ) were measured. The concentration variance of the MB and MR solutions was calculated using the light absorption spectrum intensity, and the dye degradation was calculated as:

$$
\eta=\frac{C_{\circ}-C t}{C_{\circ}} \times 100
$$

where $\mathrm{C} 0$ and $\mathrm{Ct}$ were initial and final concentrations after a certain reaction time, respectively.

\section{Results And Discussion}

In this work, we have improved an eco-friendly, pure, nontoxic method, for the generation of CuO NPs using the B. ciliata rhizome extract. (Fig. 1.). B.ciliata is widely used in traditional medicine because of its phytochemicals (bergenin, gallic acid, $(+)$ - catechin, paashaanolactone etc.) $[45,46]$. $\mathrm{CuSO}_{4} 5 \mathrm{H}_{2} \mathrm{O}$, initially metal precursor, reacts with the hydroxyl ion in water to form copper hydroxide. The phytochemicals contained in the $B$. ciliata extract are used as reducing and stabilizing. Copper oxide nanoparticles are synthesized from copper hydroxide with these phytochemicals. 


\subsection{Characterization of nanoparticles}

The first step in the characterizing of nanoparticles is the color transformation of solution (Fig. 2.) indicates the reduction of copper ions into CuO NPs using aqueous extract of $B$. ciliata. It occurs because of visual color change of solution from light brown to brick red (brownish), which is due to the excitation of surface plasmon vibrations in CuO NPs [47].

UV-Visible absorption spectrum was used for the analysis of optical properties of CuO NPs. Surface plasmon absorption of metal oxide generated an absorption peak at $260 \mathrm{~nm}$ in the spectrum. No additional peaks were found in the range of $200-500 \mathrm{~nm}$, and the absorption peak was found to be symmetric. (Fig. 3a.). The results were in good agreement with study of Kumar et al [48]. Surface plasmon absorption and collective oscillation of free conduction band electrons stimulated by electromagnetic radiation are achieved in metal oxide nanoparticles. If the wavelength of the incident light is greater than the particle diameter, a resonance will occur. Surface plasma resonance absorbance is very sensitive to the size and shape of the particles, their distance between particles, the surrounding environments and nature [49]. In the range of $4000-400 \mathrm{~cm} 1$, the FTIR spectrum was measured in solid phase using the potassium bromide pellet technique. (Fig. 3b.) gives information about the spectral peaks proposing, the occurrence of bands relevant to amide $\mathrm{N}-\mathrm{H}$ stretching $\left(3402 \mathrm{~cm}^{-1}\right)$, amide $\mathrm{C}=\mathrm{O}$ stretching $\left(1578 \mathrm{~cm}^{-1}\right)$, alkanes $\mathrm{C}=\mathrm{O}$ stretching $\left(2350 \mathrm{~cm}^{-1}\right)$, nitro $\mathrm{N}-\mathrm{O}$ bending $\left(1399 \mathrm{~cm}^{-1}\right)$. The presence of CuO NPs band at $618 \mathrm{~cm}^{-1}$ accepted to the vibrations of $\mathrm{Cu}-\mathrm{O}$. The above result confirms that the bio-active compounds present in the $B$. ciliata rhizome extract have upper hand in the production of CuO NPs. The little diversity in the peak position from original bonding show that the some of the metabolites (tannins, flavonoids, alkaloids, and carotenoids etc) are plenty in the bud extract that can produce the CuO NPs [50].

XRD analysis is used to determine the crystalline properties of NPs. In this work, XRD analysis of CuO nanoparticles obtained by green synthesis is shown in Fig. 4a. small different diffraction peaks at 32.80, $39.75,61.40$ and 71.02, that indexed the planes 111, 200, 220 and 311 of face centered cubic structure of CuO NPs with a monoclinic phase (JCPDS- 87-0717). CuO nanoparticles synthesized from $B$. ciliata rhizome extract have been shown to be crystalline in nature by XRD analysis and no other phase showing the purity of these nanoparticles has been observed. The Debye-Scherrer equation was used to measure the crystal size of the nanoparticles obtained [51-53]:

$D=K \lambda / \beta \cos \theta$

K: Scherrer's constant $(K=0.94)$, D: crystalline size, $k$ : X-ray wavelength $(0.1546 \mathrm{~nm})$, b: fullwidth at halfmaximum of the XRD line in radians, h: half diffraction angle.

The average size of CuO NPs was measured be about $20 \mathrm{~nm}$. The XRD data of the bio-synthesis CuO nanoparticles obtained in previous studies are parallel to the $\mathrm{CuO}$ nanoparticle data obtained in this study $[37,54]$. DLS analysis was used to measure the average particle size (Fig. 4b). The average particle size 
of the CuO NPs obtained accordingly is less than $50 \mathrm{~nm}$. Figure 5.a shows the SEM analysis of CuO NPs synthesized from B. ciliata. According to this SEM analysis, particles appear spherical and hexagonal, but there are also large particles formed by the combination of small particles. EDS analysis of CuO NPs synthesized by $B$. ciliata is given in Fig. 5.b. According to this analysis, elemental $\mathrm{Cu}$ is at a highly intensive important peak of elemental $\mathrm{Cu}$ and $\mathrm{O}$ with the atomic $71.8 \%$ of and $28.23 \%$ which is in suitability with the main description line of metallic CuO NPs.

Consecutive increase in redox reaction i.e., oxidation as well as reduction peaks were observed with increasing scan rate potential. Observing cathodic current peaks i.e., $15 \mu \mathrm{A}$ at $20 \mathrm{mV} / \mathrm{cm}, 28 \mu \mathrm{A}$ at $40 \mathrm{mV} / \mathrm{cm}, 40 \mu \mathrm{A}$ at $60 \mathrm{mV} / \mathrm{cm}$ and $60 \mu \mathrm{A}$ at $100 \mathrm{mV} / \mathrm{cm}$, indicating increased amount of catalytic activity due to presence of green synthesized $\mathrm{CuO}$ nanoparticles. A linear plot between scan rate vs. cathodic current peaks has been indicated in Fig. 6 . Scan rate range from $20 \mathrm{mV}$ to $100 \mathrm{mV}$ were used. Increase in scan rate corresponded to increase in cathodic current suggesting CuO NPs electrode reduction is exclusively diffusion-controlled electron transfer [55] and exhibit a strong linear relationship with a $\mathrm{R}^{2}$ value of 0.9871 .

\subsection{Antioxidant Activity}

Both the crude plant extract and the NPs were tested for phenolic and flavonoid content. Phenol content of $\mathrm{BC}$ was found to be $35.021 .23 \mathrm{mg} \mathrm{GAE} / \mathrm{mg}$. In CuO NPs synthesised from the extract, this quantity is $49.231 .66 \mathrm{mg} \mathrm{GAE} / \mathrm{mg}$. The bound flavonoid content of CuO NPs was measured (22.08 1.04 mg of QE / mg). In our sample, the B. ciliata extract contained $30.091 .28 \mathrm{mg}$ of QE / mg flavonoid material. (Fig. 7 and Table 1).

Antioxidants are compounds that prevent the oxidation of essential biological macromolecules by inhibiting the propagation of the oxidizing chain reaction. The antioxidant activity of biogenic synthesis of CuO NPs was assessed using the DPPH, ABTS, and FRAP scavenging assays, which showed that a compound's reducing power is directly proportional to its antioxidant activity. CuO NPs is found to have antioxidant properties. ABTS assays the CuO NPs (IC50 $=72.4 \mathrm{~g} / \mathrm{mL})$ and FRAP assays the CuO NPs $(I C 50=109.0 \mathrm{~g} / \mathrm{mL}$ ) for DPPH, CuO NPs (IC50 $=91.2 \mathrm{~g} / \mathrm{mL}$ ), and FRAP assays the CuO NPs (IC50 $=109.0$ $\mathrm{g} / \mathrm{mL}$ ) (Fig. 7c and 7d). For the DPPH, ABTS, and FRAP assays, Ascorbic acid was used as a norm, with IC50 values of $29.24,28.7$, and $26.3 \mathrm{~g} / \mathrm{mL}$, respectively. These study reveals that Bergenia ciliata CuO NPs are more effective at scavenging free radicals and can be used as a major antioxidant source in antioxidant-based therapies. The CuO NPs' scavenging behaviour increases as the sample concentrations increase. As compared to other green synthesised nanoparticles, the presence of proteins and amino acids, as well as carbohydrates, flavonoids, glycosides, phenolic compounds, saponins, and tannins, results in higher operation. Lower the IC50 value, greater is the hydrogen donating potential of the free radical scavengers and thus their antioxidant activity. 
Table 1

Antioxidant activity of BC and CuONPs.

\section{$\mathrm{IC}_{50}$ value $(\mu \mathrm{g} / \mathrm{mL})$}

\begin{tabular}{|llll|}
\hline Sample & ABTS & DPPH & FRAP \\
\hline BC & 138.0 & 135.2 & 144.1 \\
\hline CuO NPs & 91.25 & 72.4 & 109.0 \\
\hline AA & 28.73 & 29.24 & 26.3 \\
\hline
\end{tabular}

\subsection{Antimicrobial activity}

Nanoparticles have larger surface areas compared to large particles. This large surface area interacts more with microorganisms, providing a high amount of antimicrobial effects. Copper, which has been used as an antibacterial factor for a long time, has a high antibacterial effect by $99.9 \%$ [56]. The antimicrobial effect of $\mathrm{CuO}$ nanoparticles, which were synthesized by performing various optimizations, was investigated. According to the results of the agar well diffusion assay, the antimicrobial activity of 20 $\mathrm{mg} / \mathrm{mL} \mathrm{CuO}$ nanoparticles is effective against food pathogens. Results revealed that the CuO NPs was better effective against all two Gram positive as compare to Gram negative bacterial strains shown in Fig. 8 and Table 2. On the basis of these observations, it can be concluded that synthesised CuONPs had strong antibacterial activity against bacteria belonging to both Gram classes. CuO NPs have an important antibacterial property due to their large surface area, which helps them to make closer contact with microorganisms. By cross-linking within and between nucleic acid strands, copper ions released later can bind with DNA molecules, causing helical structure disorder. Biochemical processes are often affected by copper ions in bacterial cells. $[57,58]$. The exact mechanism behind is not known and needs to be studied further. Furthermore, the Gram negative bacteria seemed to be more resistant to CuO NPs than Gram positive bacteria. It was earlier reported that the interaction between Gram positive bacteria and nanoparticles was stronger than that of Gram negative bacteria because of the difference in cell walls between Gram positive and Gram negative bacteria. BC and CuO NPs were used to inhibit the growth of test organisms as described. The minimum inhibitory concentration (MIC) was found to be $6.25 \mu \mathrm{g} / \mathrm{mL}$ against $S$. aureus, $B$. subtilis, $S$. typhi and $25 \mu \mathrm{g} / \mathrm{mL}$ against $E$. coli (Table 3 ). 
Table 2

Zone of inhibition of CuO NPs against various pathogenic bacterial strains.

\begin{tabular}{|lllll|}
\hline Bacterial Strains & Samples & & $\begin{array}{l}\text { Positive control } \\
\text { (Ampicillin-100 mg/mL) }\end{array}$ & $\begin{array}{l}\text { Negative control } \\
\text { (dw) }\end{array}$ \\
\cline { 2 - 5 } & BC & CuO NPs & $23.8 \pm 0.76$ & ND \\
\hline S. aureus & $13.5 \pm 0.50$ & $17.8 \pm 0.41$ & ND \\
\hline B. subtilis & $12.2 \pm 0.68$ & $15.8 \pm 0.76$ & $25.6 \pm 1.58$ & ND \\
\hline S. typhi & $10.3 \pm 0.72$ & $15.0 \pm 1.02$ & $23.3 \pm 0.57$ & ND \\
\hline E. coli & $7.5 \pm 0.50$ & $11.5 \pm 0.50$ & $25.6 \pm 0.57$ & \\
\hline
\end{tabular}

Table 3

Minimum Inhibitory Concentration of BC and $\mathrm{CuO}$ NPs various pathogenic bacterial strains.

\begin{tabular}{|llll|}
\hline \multicolumn{4}{|l|}{ MIC $(\boldsymbol{\mu g} / \mathrm{mL})$} \\
\hline 1 & S.No. aureus & 25 & 6.25 \\
\hline 2 & B. subtilis & 25 & 6.25 \\
\hline 3 & S. typhi & 25 & 6.25 \\
4 & E. coli & 50 & 12.5 \\
\hline
\end{tabular}

\subsection{Photocatalytic degradation}

Figure 9 depicts the dye degradation mechanism followed by CuO NPs. Sharma and Dutta reported that hydroxy radicals were the most important reactive oxygen species that caused degradation when $\mathrm{CuO}$ NPs were used [59]. CuO NPs have been widely used as catalysts in photocatalytic degradation and reduction of contaminants [60]. Matter of fact, dark adsorption is initial step and one of the most critical aspects of the photocatalysis mechanism [61]. CuO NPs were used to study the photo degradation of cationic dyes like MB and MR when exposed to sunlight. In the presence of light radiation, the MB and MR solutions were stirred in the dark for 1 hour to establish adsorption-desorption equilibrium between the CuO NPs and dye molecules. A UV-vis spectra was then used to estimate the MB and MR concentrations. Within 135 minutes, the photocatalytic activity of $B$. ciliata rhizome extract mediated CuO NPs and the absorption peaks at 625 and $525 \mathrm{~nm}$ decreased, comprising MB and MR dye. The morphology, crystalline structure, and dimensions of NPs all play a role in photocatalytic activity, according to the literature [62]. Control experiments were carried out in the dark (both with and without $\mathrm{CuO} \mathrm{NPs)} \mathrm{to} \mathrm{rule} \mathrm{out} \mathrm{any} \mathrm{possibility} \mathrm{of} \mathrm{dye} \mathrm{self-degradation,} \mathrm{dye} \mathrm{adsorption,} \mathrm{or} \mathrm{NP} \mathrm{catalytic} \mathrm{activity} \mathrm{in} \mathrm{the}$ dark. In the absence of CuO NPs, we observed negligible dye degradation after the experiment was completed (Fig. 9c and 9d). Similarly, CuO NPs had a negligible effect on dye degradation in the dark. As a result, it was determined that the dyes did not degrade significantly in dark conditions. Furthermore, dye 
degradation experiments in the absence of a catalyst revealed negligible dye degradation. MB and MR, on the other hand, were nearly fully degraded under direct sunlight in the presence of catalyst. These researches demonstrated that a photocatalytic mechanism was responsible for dye degradation. Sunlight is a very important factor from industrial perspective. The degradation was $55,47 \%$, for MB and MR dyes, respectively within $75 \mathrm{~min}$ of photo irradiation. While it was $92 \%, 85 \%$ for MB and MR dyes, respectively within 135 min of photo irradiation. After 3 hours of irradiation, an efficiency of 92 percent and 85 percent is obtained, indicating that integrating CuO NPs species into the solution serves a primary function in the improvement of photodegradation, as shown (Fig. 9e). The degradation of MB dye was observed higher as compared to MR dyes. It has been reported that the catalytic activity of a nano-catalyst is strongly influenced by the morphology and size of nanoparticles, as well as process of energy transfer, photogenerated carriers generation and consumption [63]. Balgude et al. used $\mathrm{Sn}_{3} \mathrm{O}_{4}$ nanoparticles to demonstrate the same form of degradation of MB dye within 60 minutes under sunlight irradiation [64]. Under UV light irradiation, Sonia et al. (2015) degraded the MB dye in 180 minutes using CuO nanoparticles [65].

Table 4

Comparative assessment of dyes degradation efficiency using different photocatalysts

\begin{tabular}{|c|c|c|c|c|c|c|}
\hline NPs & Dye & $\begin{array}{l}\text { Catalyst } \\
\text { concentration }\end{array}$ & $\begin{array}{l}\text { Dye } \\
\text { concentration }\end{array}$ & $\begin{array}{l}\text { Time } \\
\text { (min) }\end{array}$ & $\begin{array}{l}\text { \% } \\
\text { degradation }\end{array}$ & Reference \\
\hline \multirow[t]{2}{*}{$\mathrm{CuO}$} & $\begin{array}{l}\text { Congo } \\
\text { red }\end{array}$ & $1 \mathrm{mg} / \mathrm{mL}$ & $10 \mathrm{mg} / \mathrm{L}$ & $60 \mathrm{~min}$ & 90 & [66] \\
\hline & $\begin{array}{l}\text { Nile blue } \\
\text { (NB) }\end{array}$ & 40 ppm & $1 \mathrm{mg} / \mathrm{mL}$ & $120 \mathrm{~min}$ & 93 & [67] \\
\hline \multirow[t]{2}{*}{$\mathrm{ZnO}$} & MV6B & $0.50 \mathrm{~g}$ & $100 \mathrm{~mL}$ & 210 & 68 & [68] \\
\hline & $\begin{array}{l}\text { Reactive } \\
\text { black } 5\end{array}$ & $3 \mathrm{~g} / \mathrm{L}$ & $496 \mathrm{mg} / \mathrm{L}$ & $60 \mathrm{~min}$ & 60 & [69] \\
\hline \multirow[t]{2}{*}{$\mathrm{CuO}$} & MB & 20 ppm & $10 \mathrm{mg} / \mathrm{mL}$ & $135 \mathrm{~min}$ & 92 & Present \\
\hline & MR & 20 ppm & $10 \mathrm{mg} / \mathrm{mL}$ & $135 \min$ & 85 & study \\
\hline
\end{tabular}

\section{Mechanism}

Figure 10 illustrates the mechanism for photocatalytic activity. By generating holes in the valence band, a source of light induces electrons to excite from the valence to the conduction band. The photocatalyst holes oxidise the $\mathrm{H}_{2} \mathrm{O}$ molecules in the reaction sample to more reactive $\mathrm{OH}$ radicals. Owing to the presence of excited electrons in the $\mathrm{CB}$, the oxygen molecule gets reduced to $\mathrm{O}^{-2}$ radicals, and $\mathrm{H}_{2} \mathrm{O}_{2}$ gets reduced to $\mathrm{OH}$ radicals. The oxidative decomposition of dye to $\mathrm{CO}_{2}, \mathrm{H}_{2} \mathrm{O}$, and other mineralization products can be caused by the oxide and hydroxyl radicals formed by $\mathrm{CuO}$ nanoparticles [70-73]. 


\section{Conclusion}

As conclusion, we demonstrated a simple and environmentally friendly method for producing stable $\mathrm{CuO}$ NPs by using $B$. ciliata rhizome extract as a reducing and stabilising agent. The SPR characteristic peak at $260 \mathrm{~nm}$ is noticeable in the UV-visible absorption range. $\mathrm{Cu}-\mathrm{O}$ bonding was confirmed by FTIR spectra, and XRD patterns revealed monoclinic phase with an average grain size of $20 \mathrm{~nm}$. The particles tend to be almost highly stable and spherical in form, according to SEM images. CuO NPs' elemental composition was verified by EDX examination. Furthermore, the CuO NPs synthesized had a high level of activity against Gram positive bacteria (S. aureus). CuO NPs synthesised by the green method reveals substantial activity in in vitro antioxidant assays using various methods. Photocatalytic activity of $\mathrm{CuO}$ NPs against cationic dye has also been demonstrated. This is the first study on bio-inspired green synthesis of $\mathrm{CuO}$ NPs from B. ciliata rhizome extract, confirming their antimicrobial, antioxidant, and photocatalytic properties. Thus could pave a way for the futuristic synthesis of environmentally benign, cost effective CuO NPs from medicinal plants.

\section{Declarations}

\section{Acknowledgment}

The authors acknowledge Vice-Chancellor, Shoolini University, Solan, for providing infrastructure support to conduct the research work. Authors are highly thankful to the School of Bioengineering and Food Technology, Shoolini University, Solan, India.

\section{Compliance with ethical standards}

Author 1 declare that she has no conflict of interests.

Author 2 declare that she has no conflict of interests.

Author 3 declare that he has no conflict of interests.

Author 4 declare that he has no conflict of interests.

Author 5 declare that he has no conflict of interests.

\section{Ethical approval:}

This article does not contain any studies with human participants or animals performed by any of the authors.

\section{References}

1. C. Li, H. Tan, J. Lin, X. Luo, S. Wang, J. You, Y. M. Kang, Y. Bando, Y. Yamauchi, and J. Kim, Nano Today (2018). 
2. C. Li, M. Iqbal, J. Lin, X. Luo, B. Jiang, V. Malgras, K. C. W. Wu, J. Kim, and Y. Yamauchi, Acc. Chem. Res. (2018).

3. H. Ataee-Esfahani, J. Liu, M. Hu, N. Miyamoto, S. Tominaka, K. C. W. Wu, and Y. Yamauchi, Small (2013).

4. C. Li, M. Iqbal, B. Jiang, Z. Wang, J. Kim, A. K. Nanjundan, A. E. Whitten, K. Wood, and Y. Yamauchi, Chem. Sci. (2019).

5. H. Ataee-Esfahani, L. Wang, and Y. Yamauchi, Chem. Commun. (2010).

6. P. Boomi, G. P. Poorani, S. Palanisamy, S. Selvam, G. Ramanathan, S. Ravikumar, H. Barabadi, H. G. Prabu, J. Jeyakanthan, and M. Saravanan, J. Clust. Sci. (2019).

7. K. Kanagamani, P. Muthukrishnan, K. Shankar, A. Kathiresan, H. Barabadi, and M. Saravanan, J. Clust. Sci. (2019).

8. R. Balachandar, P. Gurumoorthy, N. Karmegam, H. Barabadi, R. Subbaiya, K. Anand, P. Boomi, and M. Saravanan, J. Clust. Sci. (2019).

9. F. Midik Ertosun, K. Cellat, O. Eren, Ş. Gül, E. Kuşvuran, and F. Şen, SN Appl. Sci. (2019).

10. M. Ali, B. Kim, K. D. Belfield, D. Norman, M. Brennan, and G. S. Ali, Mater. Sci. Eng. C (2016).

11. J. Y. Song and B. S. Kim, Bioprocess Biosyst. Eng. (2009).

12. B. Demirkan, S. Bozkurt, A. Şavk, K. Cellat, F. Gülbağca, M. S. Nas, M. H. Alma, and F. Sen, Sci. Rep. (2019).

13. R. Singh, P. Wagh, S. Wadhwani, S. Gaidhani, A. Kumbhar, J. Bellare, and B. A. Chopade, Int. J. Nanomedicine (2013).

14. V. Kulkarni Hutatma Rajguru Mahavidyalya Rajgurunagar, P. Kulkarni Hutatma Rajguru Mahavid, V. D. Kulkarni, and P. S. Kulkarni, Int. J. Chem. Stud. (2013).

15. S. K. Das, C. Dickinson, F. Lafir, D. F. Brougham, and E. Marsili, Green Chem. (2012).

16. D. Bhattacharya and R. K. Gupta, Crit. Rev. Biotechnol. (2005).

17. A. Rostami-Vartooni, M. Nasrollahzadeh, and M. Alizadeh, J. Alloys Compd. (2016).

18. A. Anwar, A. Masri, K. Rao, K. Rajendran, N. A. Khan, M. R. Shah, and R. Siddiqui, Sci. Rep. (2019).

19. E. S. Al-Sheddi, N. N. Farshori, M. M. Al-Oqail, S. M. Al-Massarani, Q. Saquib, R. Wahab, J. Musarrat, A. A. Al-Khedhairy, and M. A. Siddiqui, Bioinorg. Chem. Appl. (2018).

20. B. Şahin, A. Aygün, H. Gündüz, K. Şahin, E. Demir, S. Akocak, and F. Şen, Colloids Surfaces B Biointerfaces (2018).

21. M. Murali, C. Mahendra, Nagabhushan, N. Rajashekar, M. S. Sudarshana, K. A. Raveesha, and K. N. Amruthesh, Spectrochim. Acta - Part A Mol. Biomol. Spectrosc. (2017).

22. T. Lammers, S. Aime, W. E. Hennink, G. Storm, and F. Kiessling, Acc. Chem. Res. (2011).

23. S. S. Ravi, L. R. Christena, N. Saisubramanian, and S. P. Anthony, Analyst (2013).

24. V. Kumar, K. Singh, S. Panwar, and S. K. Mehta, Int. Nano Lett. (2017). 
25. S. C. Capaldi Arruda, A. L. Diniz Silva, R. Moretto Galazzi, R. Antunes Azevedo, and M. A. Zezzi Arruda, Talanta (2015).

26. P. R. Prasad, S. Kanchi, and E. B. Naidoo, J. Photochem. Photobiol. B Biol. (2016).

27. J. Suárez-Cerda, H. Espinoza-Gómez, G. Alonso-Núñez, I. A. Rivero, Y. Gochi-Ponce, and L. Z. FloresLópez, J. Saudi Chem. Soc. (2017).

28. A. Tadjarodi and R. Roshani, Curr. Chem. Lett. (2014).

29. J. M. Tranquada, B. J. Sternlieb, J. D. Axe, Y. Nakamura, and S. Uchida, Nature (1995).

30. Y. N. Chang, M. Zhang, L. Xia, J. Zhang, and G. Xing, Materials (Basel). (2012).

31. V. Rajkumar, G. Guha, R. A. Kumar, and L. Mathew, Rec. Nat. Prod. (2010).

32. S. Saha and R. J. Verma, Arab J. Urol. (2013).

33. S. Sinha, T. Murugesan, M. Pal, and B. P. Saha, Phytomedicine (2001).

34. D. Gehlot and A. Bohra, Indian J. Med. Sci. (2000).

35. U. D. Chandrareddy, A. S. Chawla, D. Mundkinajeddu, R. Maurya, and S. S. Handa, Phytochemistry (1998).

36. K. Dhalwal, V. M. Shinde, Y. S. Biradar, and K. R. Mahadik, J. Food Compos. Anal. (2008).

37. R. Sankar, P. Manikandan, V. Malarvizhi, T. Fathima, K. S. Shivashangari, and V. Ravikumar, Spectrochim. Acta - Part A Mol. Biomol. Spectrosc. (2014).

38. V. L. Singleton and J. A. J. Rossi, Am. J. Enol. Vinic. (1965).

39. A. Meda, C. E. Lamien, M. Romito, J. Millogo, and O. G. Nacoulma, Food Chem. (2005).

40. R. Re, N. Pellegrini, A. Proteggente, A. Pannala, M. Yang, and C. Rice-Evans, Free Radic. Biol. Med. (1999).

41. L. Barros, M. J. Ferreira, B. Queirós, I. C. F. R. Ferreira, and P. Baptista, Food Chem. (2007).

42. I. F. F. Benzie and J. J. Strain, Anal. Biochem. (1996).

43. C. Perez, M. Pauli, and P. Bazerque, Acta Biol Med Exp (1990).

44. Clinical and Laboratory Standards Institute (CLSI), Methods for Dilution Antimicrobial Susceptibility Tests f or Bacteria That Grow Aerobically; Approved St Andard-Ninth Edition. (2012).

45. R. Dharmender, T. Madhavi, A. Reena, and A. Sheetal, Pharm. Anal. Acta (2010).

46. V. Kumar and D. Tyagi, Int.J.Curr.Microbiol.App.Sci (2013).

47. Krithiga N, Jayachitra A, and Rajalakshmi A, Indian J. Nanosci. (2013).

48. P. P. N. V. Kumar, U. Shameem, P. Kollu, R. L. Kalyani, and S. V. N. Pammi, Bionanoscience (2015).

49. P. K. Jain, X. Huang, I. H. El-Sayed, and M. A. El-Sayed, Plasmonics (2007).

50. G. Ren, D. Hu, E. W. C. Cheng, M. A. Vargas-Reus, P. Reip, and R. P. Allaker, Int. J. Antimicrob. Agents (2009).

51. K. Dulta, G. Koşarsoy Ağçeli, P. Chauhan, R. Jasrotia, and P. K. Chauhan, J. Inorg. Organomet. Polym. Mater. (2020). 
52. R. Jasrotia, P. Puri, A. Verma, and V. P. Singh, J. Solid State Chem. (2020).

53. R. Jasrotia, Suman, V. Pratap Singh, R. Kumar, R. Verma, and A. Chauhan, Results Phys. (2019).

54. G. Sangeetha, S. Rajeshwari, and R. Venckatesh, Mater. Res. Bull. (2011).

55. J. I. Gowda and S. T. Nandibewoor, Asian J. Pharm. Sci. (2014).

56. M. J. Hajipour, K. M. Fromm, A. Akbar Ashkarran, D. Jimenez de Aberasturi, I. R. de Larramendi, T. Rojo, V. Serpooshan, W. J. Parak, and M. Mahmoudi, Trends Biotechnol. (2012).

57. J. H. Kim, H. Cho, S. E. Ryu, and M. U. Choi, in Arch. Biochem. Biophys. (2000).

58. Zarrindokht Emami-Karvani, African J. Microbiol. Res. (2012).

59. A. Sharma and R. K. Dutta, RSC Adv. (2015).

60. N. Pradhan, A. Pal, and T. Pal, Colloids Surfaces A Physicochem. Eng. Asp. (2002).

61. R. Slama, J. El Ghoul, I. Ghiloufi, K. Omri, L. El Mir, and A. Houas, J. Mater. Sci. Mater. Electron. (2016).

62. J. R. Nakkala, R. Mata, K. Raja, V. Khub Chandra, and S. R. Sadras, Mater. Sci. Eng. C (2018).

63. M. D. Balakumaran, R. Ramachandran, P. Balashanmugam, D. J. Mukeshkumar, and P. T. Kalaichelvan, Microbiol. Res. (2016).

64. S. D. Balgude, Y. A. Sethi, B. B. Kale, N. R. Munirathnam, D. P. Amalnerkar, and P. V. Adhyapak, RSC Adv. (2016).

65. S. Sonia, S. Poongodi, P. S. Kumar, D. Mangalaraj, N. Ponpandian, and C. Viswanathan, Mater. Sci. Semicond. Process. (2015).

66. M. Aminuzzaman, L. M. Kei, and W. H. Liang, in AIP Conf. Proc. (2017).

67. J. Singh, V. Kumar, K. H. Kim, and M. Rawat, Environ. Res. (2019).

68. M. A. Subhan, M. R. Awal, T. Ahmed, and M. Younus, Acta Metall. Sin. (English Lett. (2014).

69. S. Amisha, K. Selvam, N. Sobana, and M. Swaminathan, J. Korean Chem. Soc. (2008).

70. S. B. Patil, H. S. Bhojya Naik, G. Nagaraju, R. Viswanath, and S. K. Rashmi, Eur. Phys. J. Plus (2017).

71. R. Arunachalam, S. Dhanasingh, B. Kalimuthu, M. Uthirappan, C. Rose, and A. B. Mandal, Colloids Surfaces B Biointerfaces (2012).

72. D. Hariharan, A. Jegatha Christy, J. Mayandi, and L. C. Nehru, Mater. Lett. (2018).

73. S. A. Ansari, S. G. Ansari, H. Foaud, and M. H. Cho, New J. Chem. (2017).

\section{Figures}




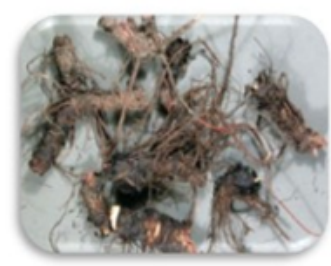

Fresh rhizome of plant

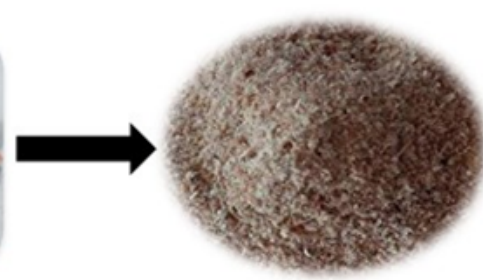

Powdered rhizomes

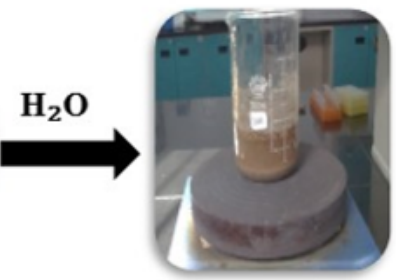

Boliing at Hot Plate

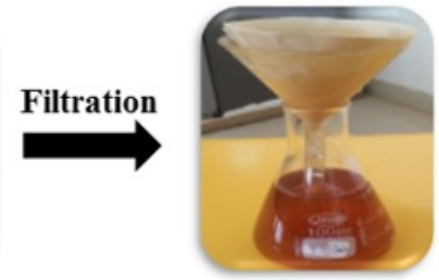

Aqueous rhizome extract

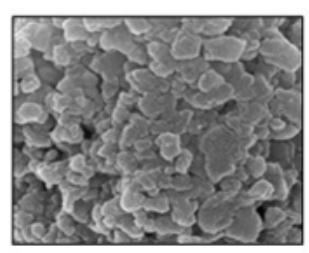

Characterization of NPs

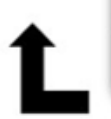

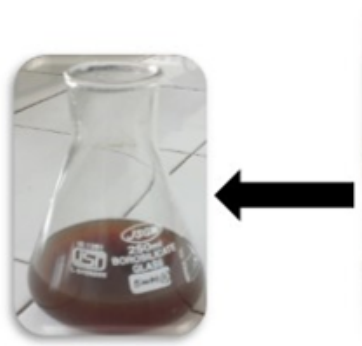

Formation of NPs

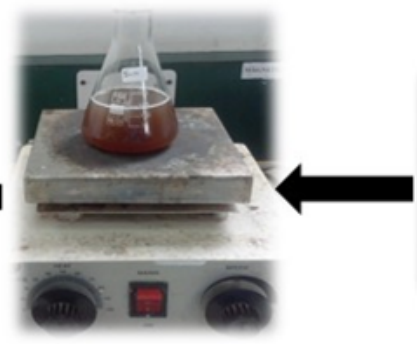

Magnetic Stirring $\left(60^{\circ} \mathrm{C}\right)$

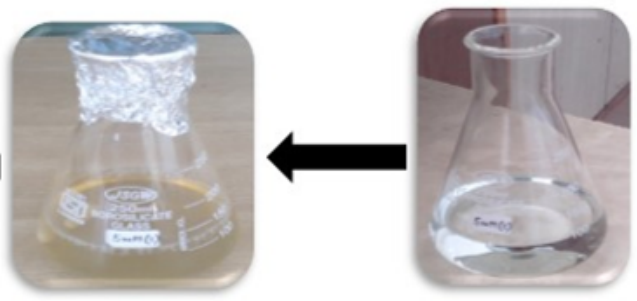

Rhizome extract + copper Copper sulphate Solution sulphate solution

\section{Figure 1}

Schematic of plant-mediated $\mathrm{CuO}$ nanoparticle synthesis
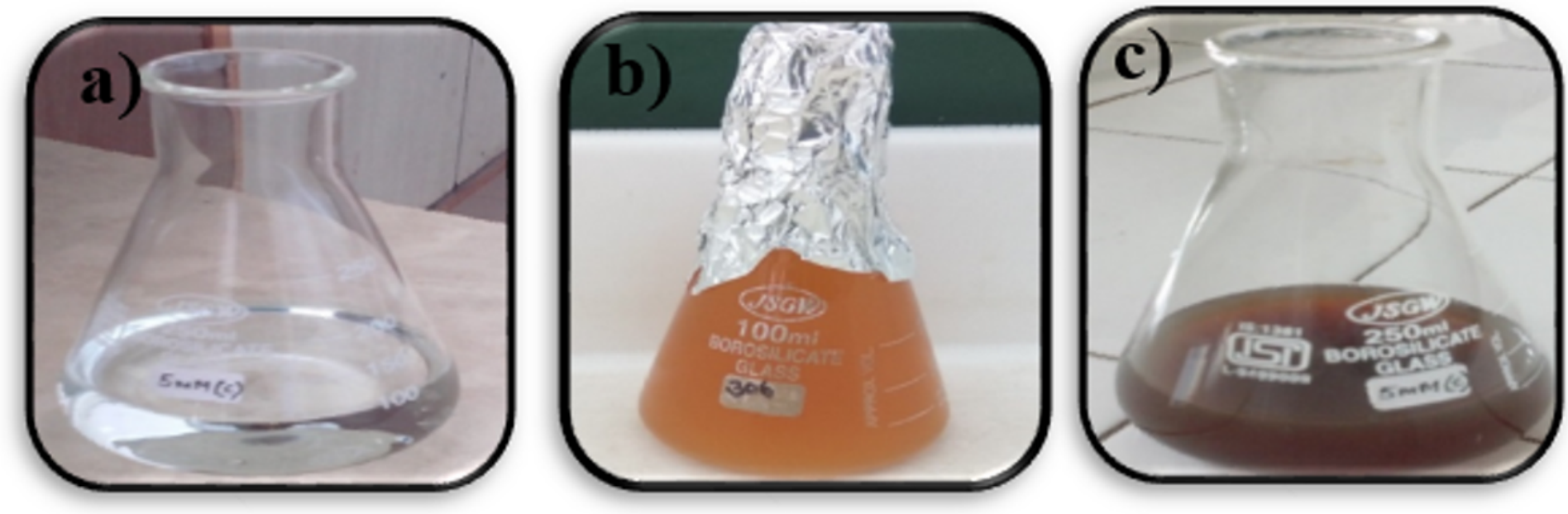

Figure 2

CuO NPs synthesis visual observation (a) copper sulphate solution (b) initial colour transition (c) final colour transition. 
a)

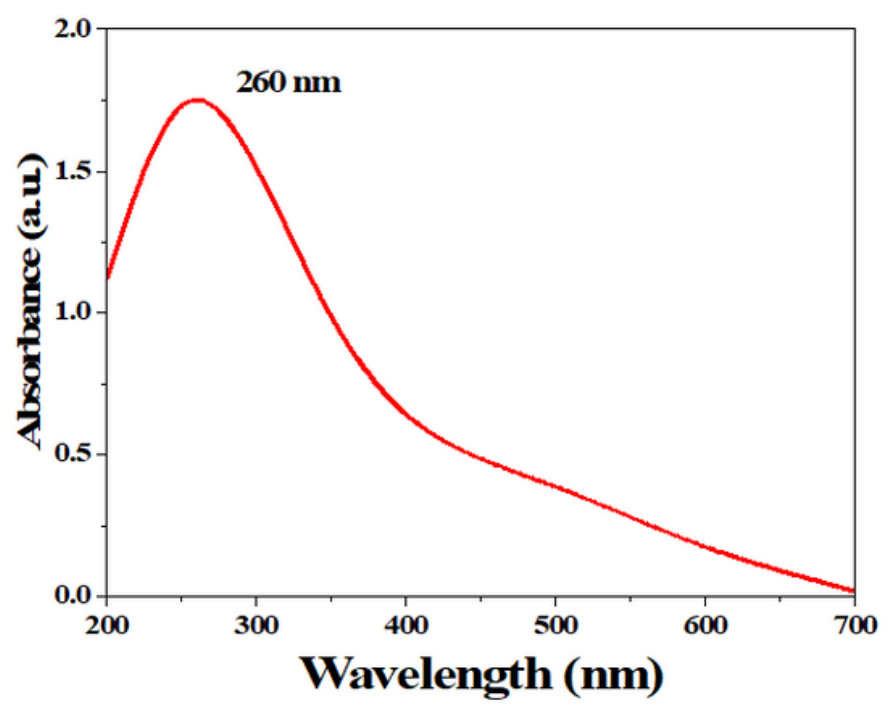

b)

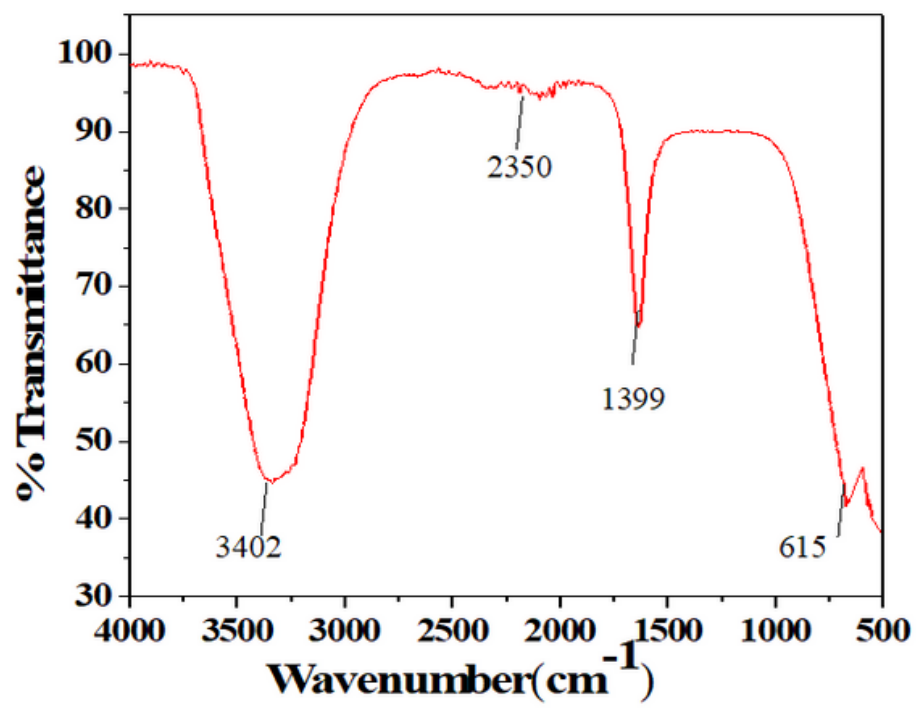

Figure 3

a) UV-Visible spectra of CuO NPs and b) FTIR Spectra of CuO

a)

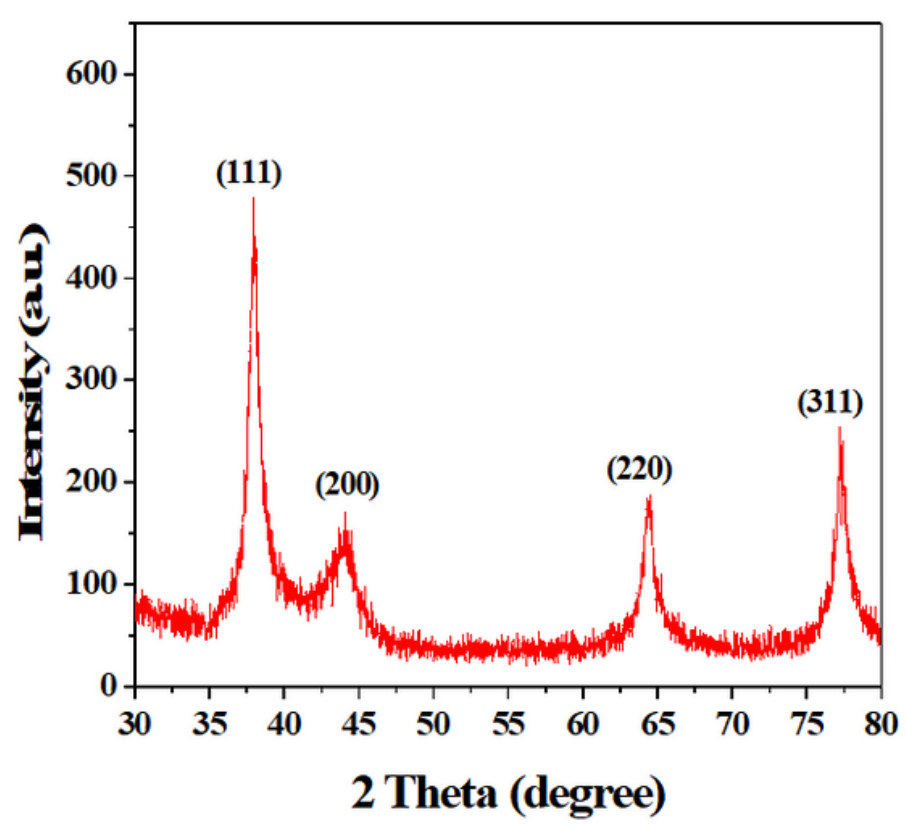

b)

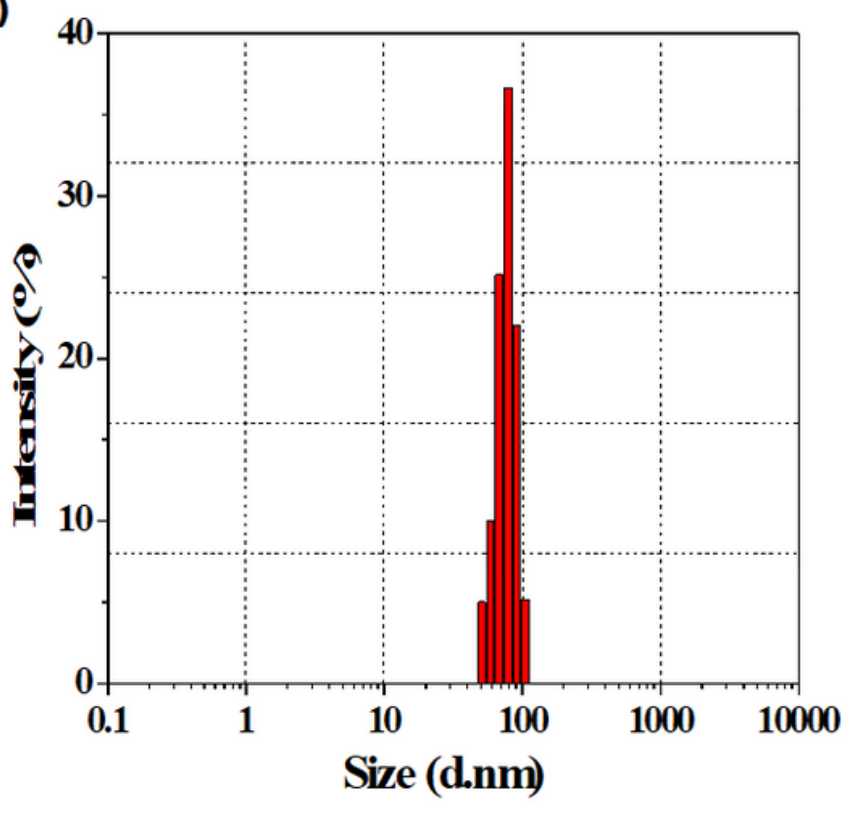

Figure 4

a) XRD pattern of CuO NPs and b) DLS pattern of CuO NPs 
a)

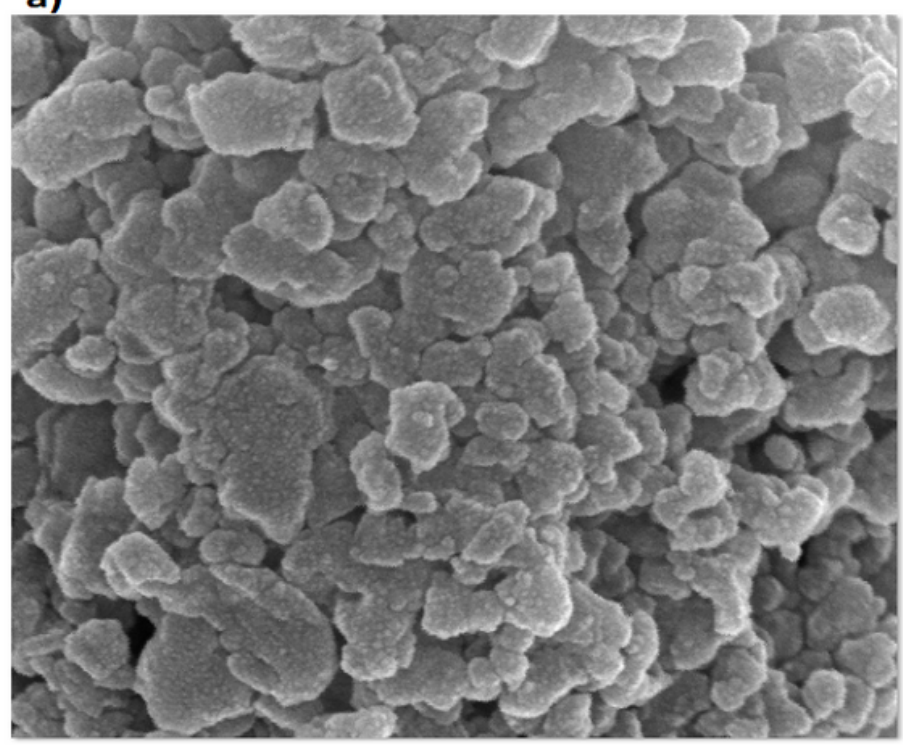

b)

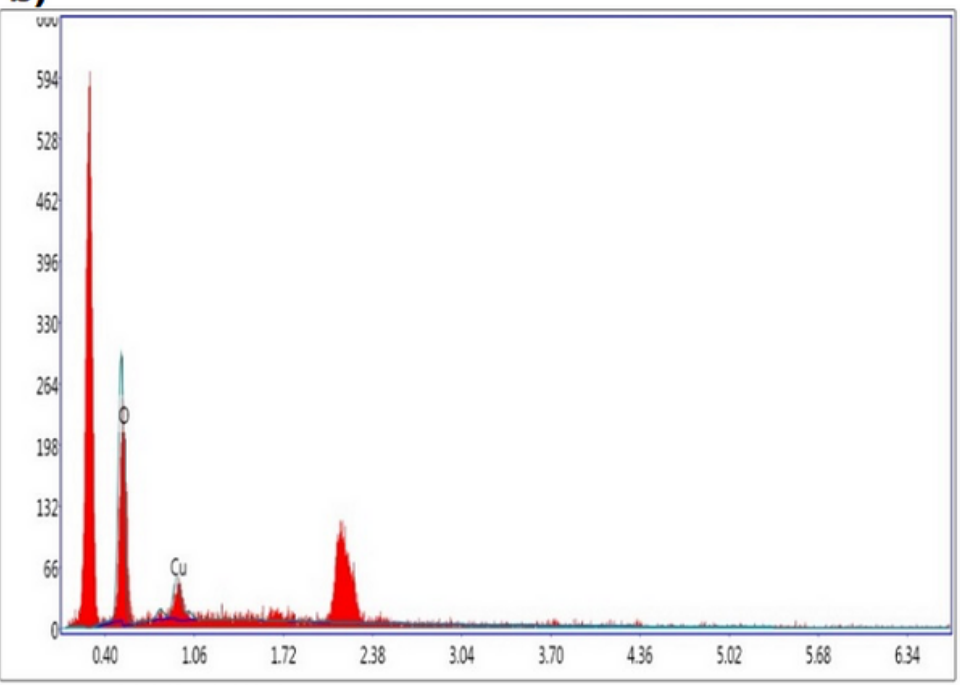

Lsec 30.00 Cints 0.000 keV Det Octane Plus Det

\section{Figure 5}

a) SEM images of the CuO NPs at $500 \mu \mathrm{m}$ b) EDS analysis of CuO NPs.

a)

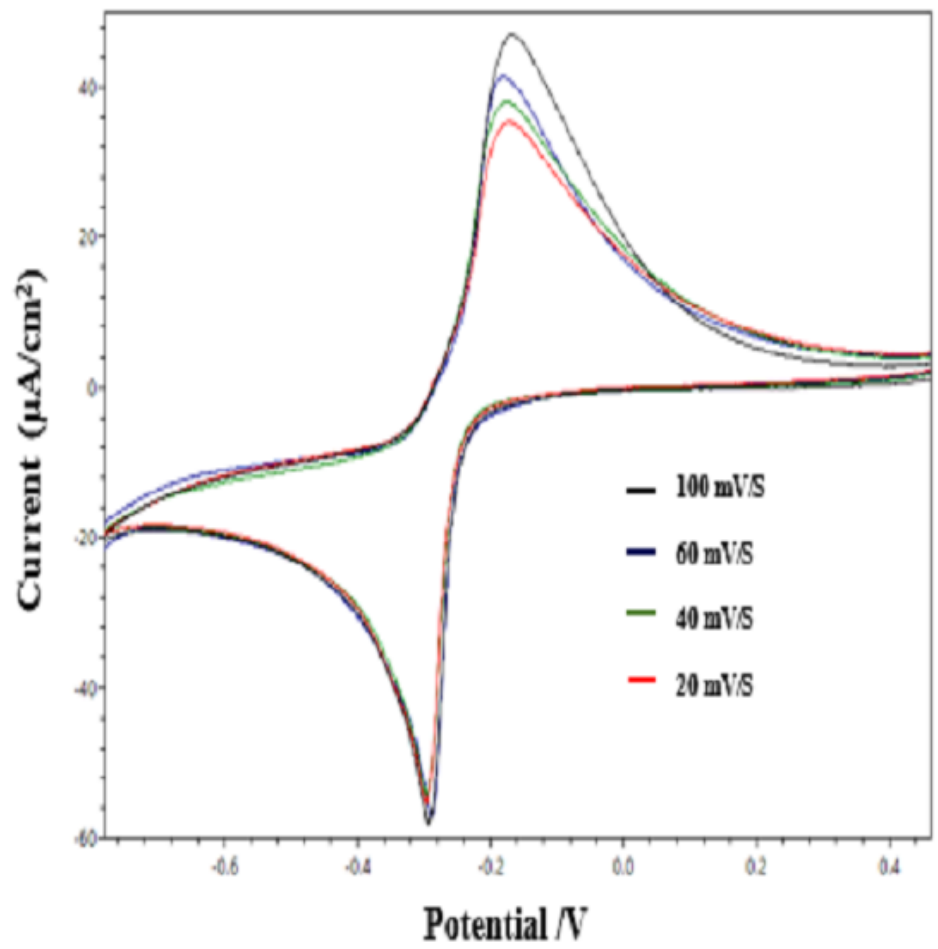

b)

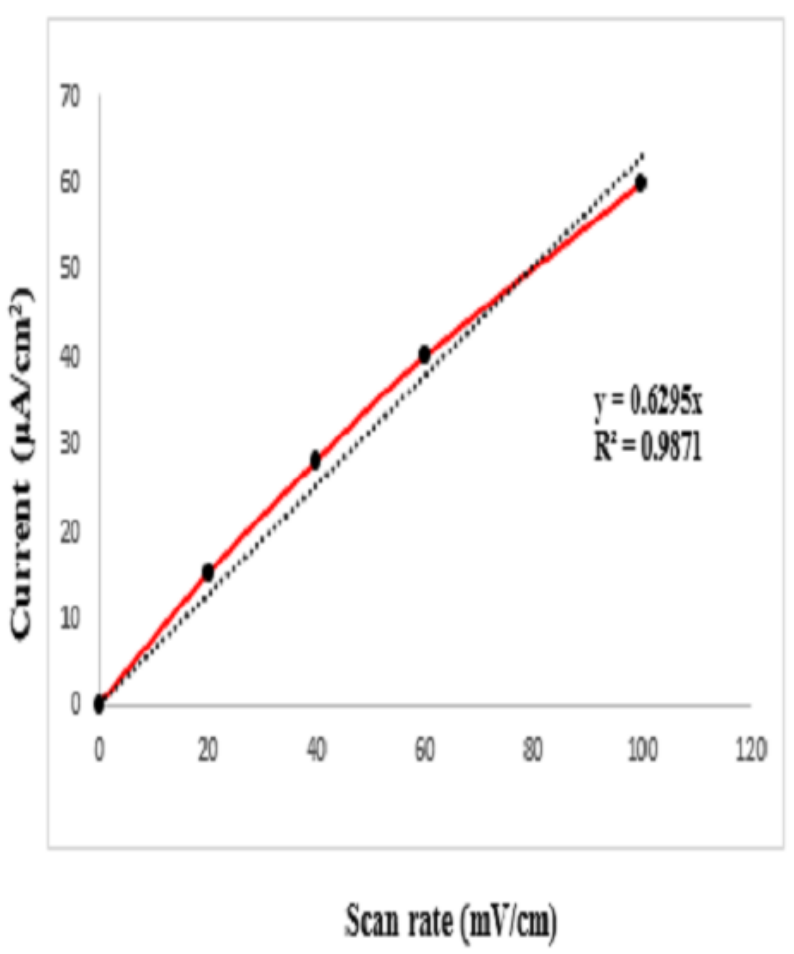

Figure 6

a) Cyclic voltammogram of $\mathrm{CuO}$ nanoparticles b) Linear plot between scan rate vs. cathodic current. 
a)
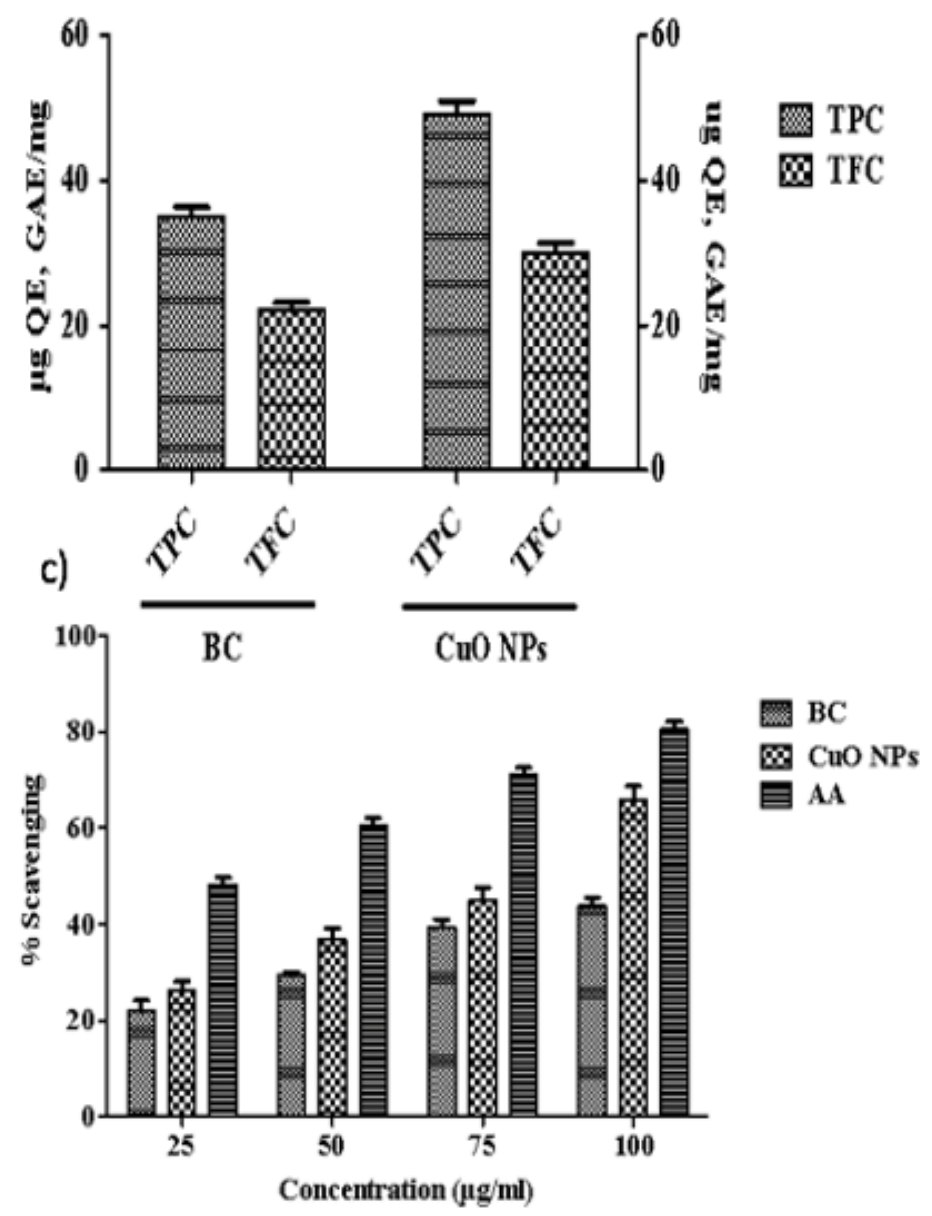

b)

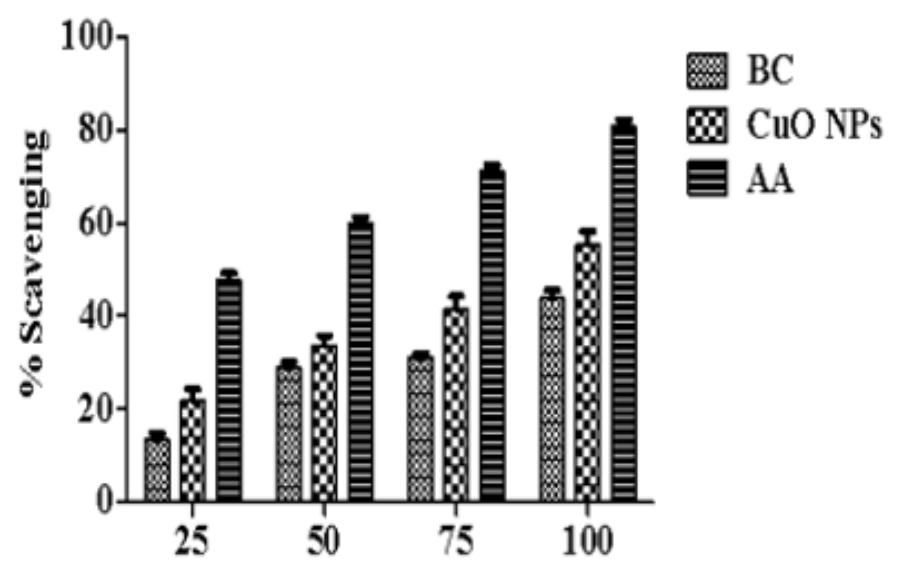

d)

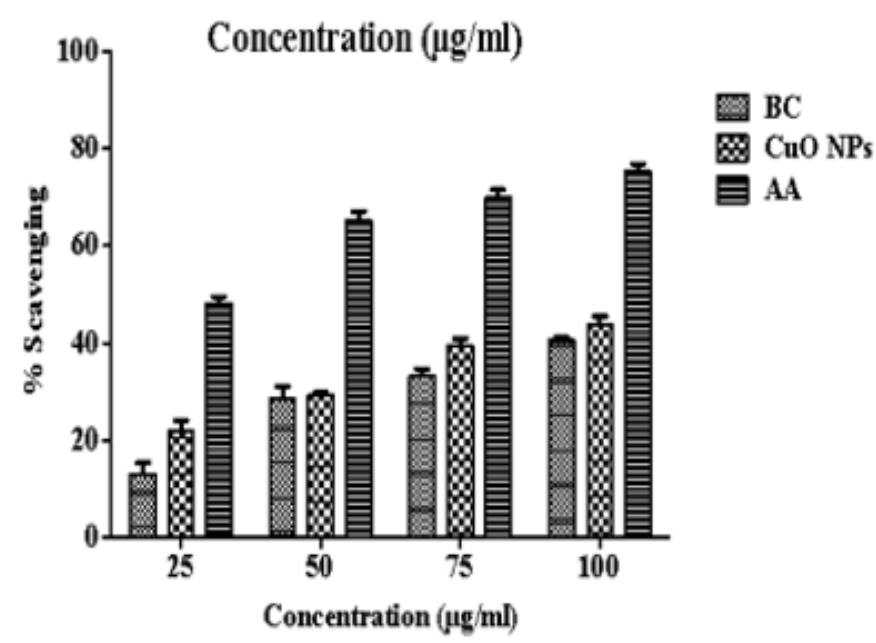

Figure 7

Biological activity of Berginia ciliata (BC) and CuONPs a) Total phenolic and total flavonoid content $b$ ) DPPH assay c) ABTS assay d) FRAP assay 

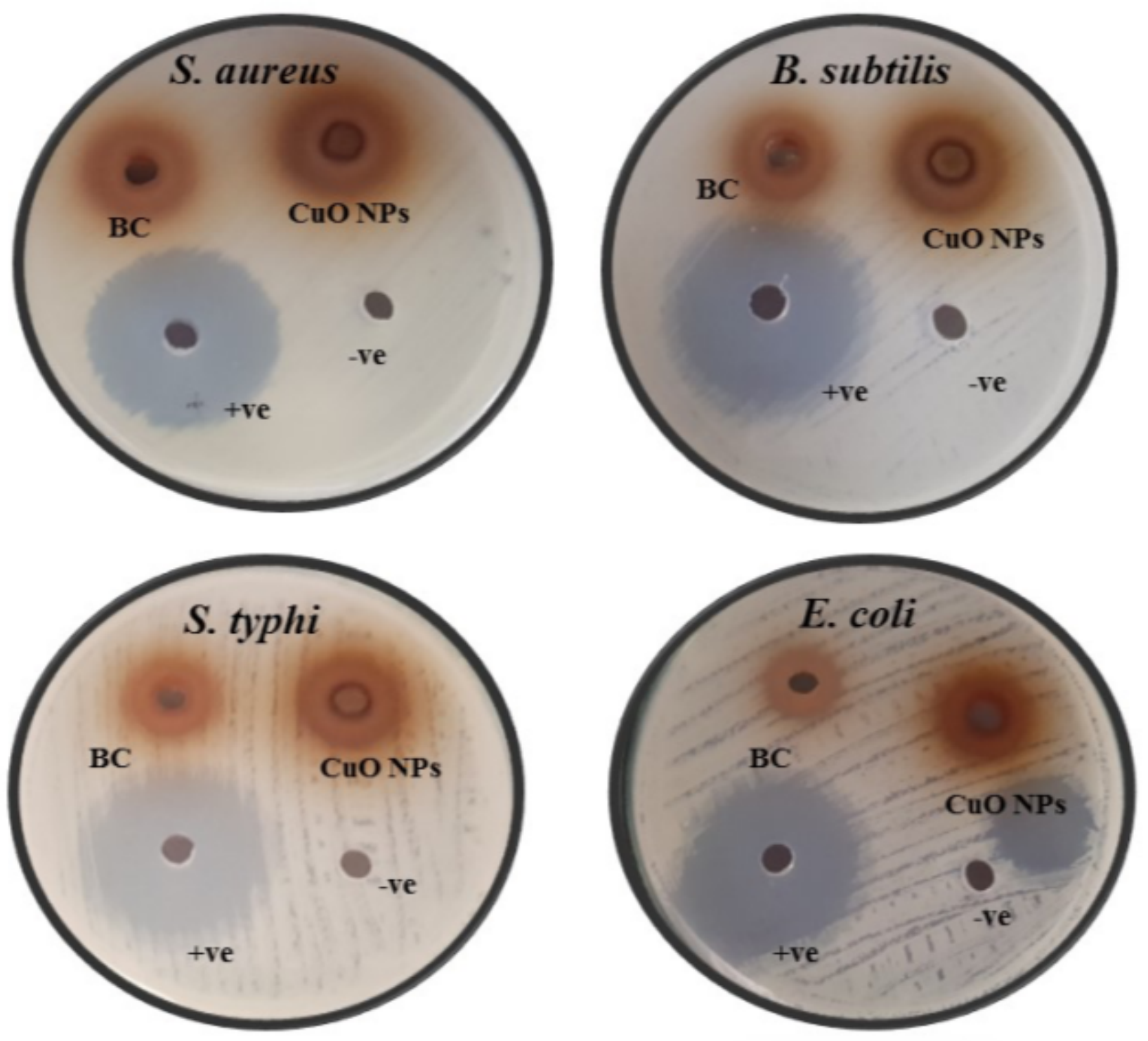

Figure 8

Zone of inhibition of CuO NPs against various pathogenic bacterial strains. 
a)

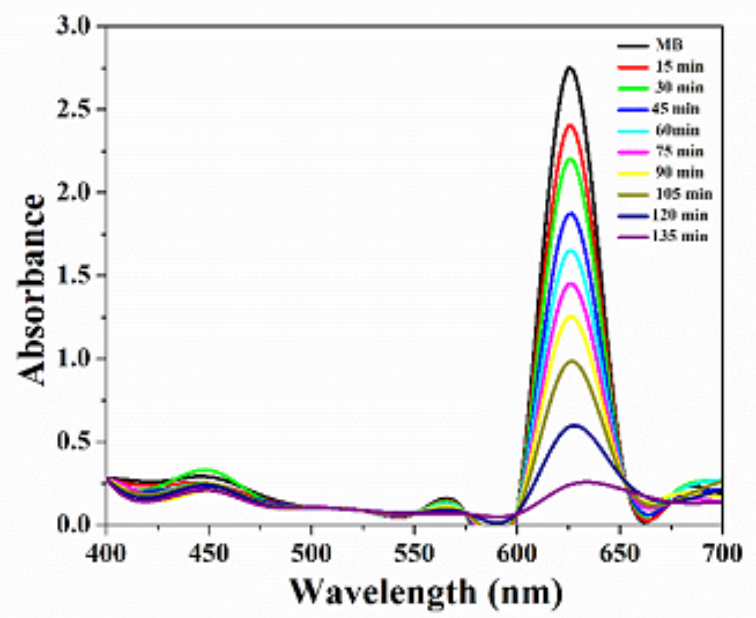

c)

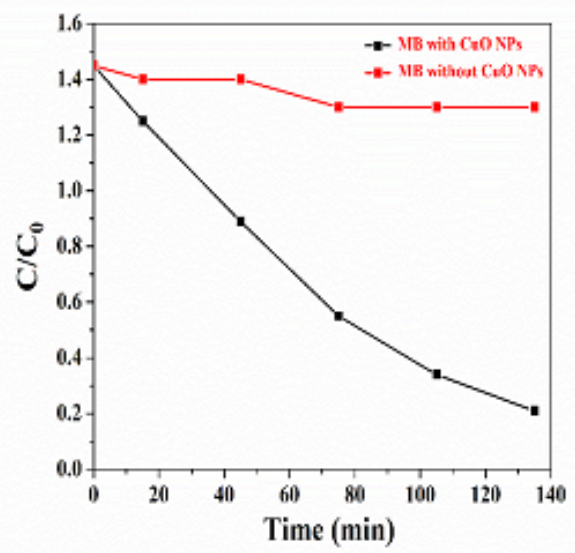

b)

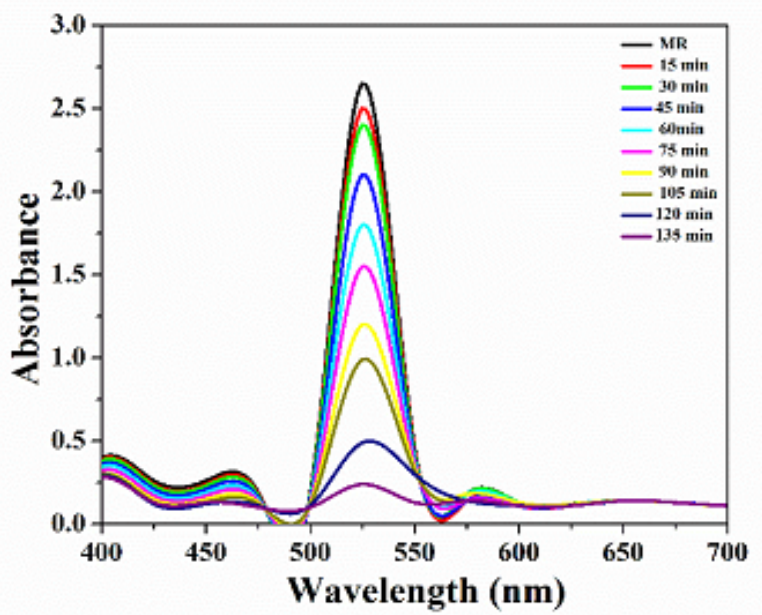

e)

Figure 9
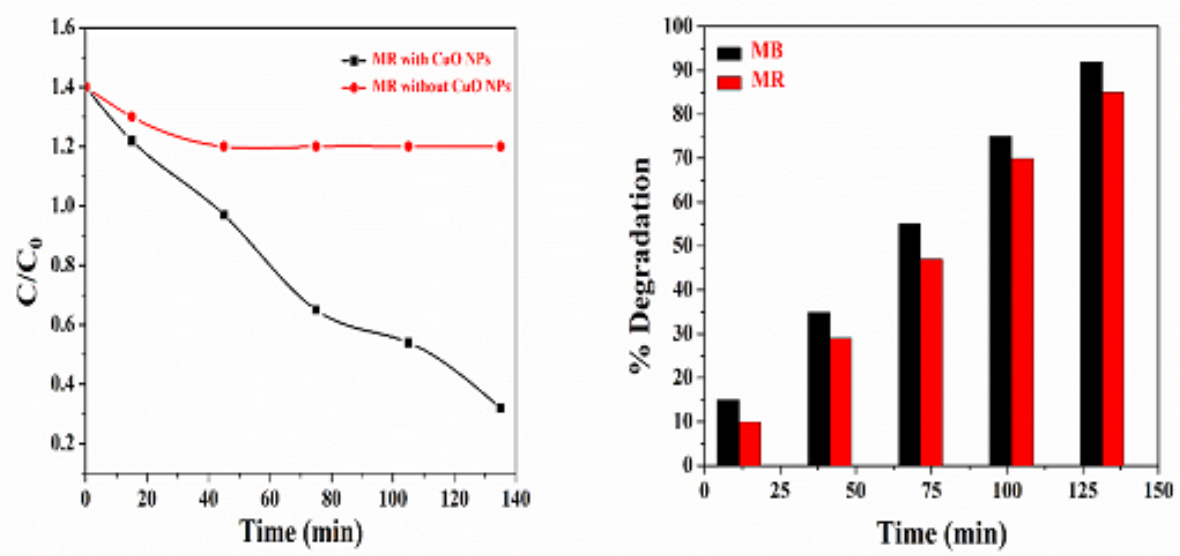

UV- visible spectra of CuO NPs during dye degradation a) MB under sunlight b) and MR under sunlight; c) MB d) MR, degradation of dyes in the dark and under sunlight in the absence and presence of catalyst; e) the photocatalytic degradation of CuO NPs, methylene blue (MB) and methyl red (MR) dyes under sunlight. 


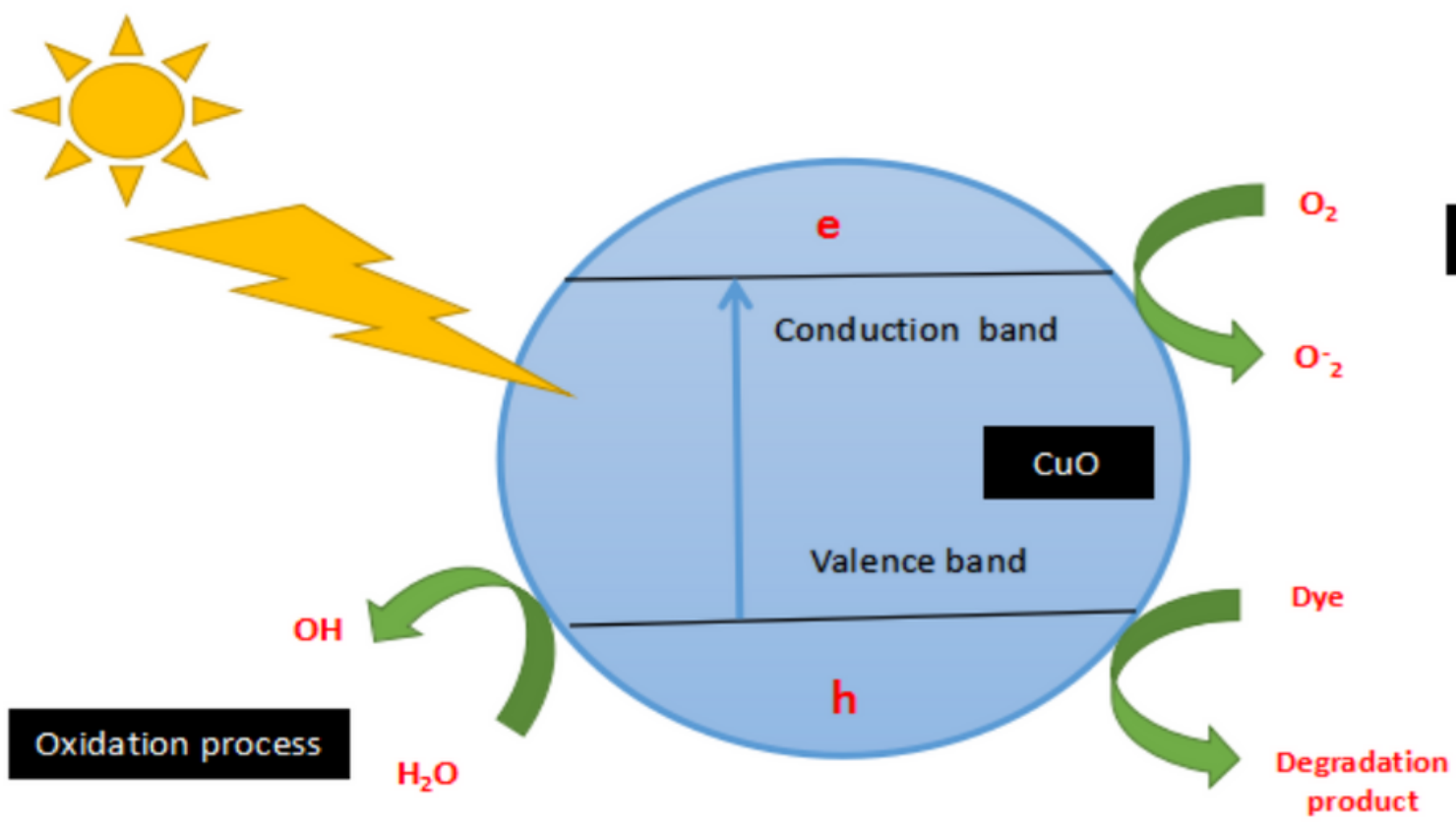

Figure 10

A schematic diagram of CuO NPs as a photocatalyst under visible light degrading organic dye. 